\title{
Membandingkan Nilai Percepatan Gravitasi Bumi di Beberapa Tempat dengan Menggunakan Bandul Sederhana di Kabupaten Sumba Barat Daya
}

\author{
Yohanis Umbu Kaleka ${ }^{1}$, Oktavianus Deke, Gregorius Nani ${ }^{\mathbf{3}}$ \\ ${ }^{1,3}$ Program Studi Pendidikan Fisika, STKIP Weetebula, Sumba Barat Daya, NTT \\ ${ }^{2}$ Program Studi Pendidikan IPA STKIP Weetebula, Sumba Barat Daya, NTT
}

*Yohanis Umbu Kaleka, Program
Studi Pendidikan Fisika, STKIP
Weetebula, Sumba Barat Daya,
NTT, Indonesia
Email: yohanumbu07@gmail.com

\begin{abstract}
Abstrak: Tujuan penelitian ini untuk menghitung besar nilai percepatan gravitasi bumi pada beberapa tempat dan mengetahui perbedaan nilai gravitasi bumi di Kabupaten Sumba Barat Daya. Jenis penelitian yang digunakan adalah eksperimen murni (true experimental) yaitu metode eksperimen yang paling mengikuti prosedur dan memenuhi syarat-syarat eksperimen. Pengambilan data dilakukan di setiap titik sampel yang tersebar di sepuluh kecamatan di wilayah kabupaten Sumba Barat Daya yang telah di tentukan berdasarkan teknik sampling yakni cluster sampling. Hasil yang di peroleh adalah rata-rata nilai gravitasi bumi di Kabupaten Sumba Barat Daya sebesar 9,98 m/s2.
\end{abstract}

Kata Kunci: Gravitasi Bumi, Pengukuran, Bandul, Eksperimen, Sumba Barat Daya.

\section{Pendahuluan}

Fisika berasal dari istilah bahasa Yunani "fysis", yang artinya "alam". Dalam hal ini, fisika adalah salah satu cabang ilmu pengetahuan alam (sains) yang berisi kajian tentang sifat dasar materi (zat) dan energi serta interaksi antara materi (zat) dengan energi tersebut (Novidawati, 2019).

Fisika merupakan salah satu cabang Ilmu Pengetahuan Alam (IPA) yang berkembang dari rasa keingintahuan manusia terhadap sifat keteraturan yang ada di alam yang belum terpecahkan. Rasa keingintahuan yang tinggi dimiliki manusia terhadap misteri alam semesta yang tersimpan di balik pengetahuan yang terbatas mendorong setiap orang untuk melakukan berbagai cara guna mengungkap misteri yang tersembunyi di balik alam semesta, hal ini memicu timbulnya pertanyaan-pertanyaan reflektif terhadap fenomena alam yang terjadi disetiap masa. Oleh karena itu, banyak hipotesis, eksperimen dan penelitian yang dilakukan para ilmuan atau Fisikawan disetiap masa untuk mengungkap berbagai fenomena alam yang terjadi dan terkadang tidak masuk akal namun benar-benar ada dan sangat berpengaruh pada kehidupan di setiap masa.

Pada awalnya ilmu fisika juga berkembang dari dunia filosofi dimana manusia terus memperhatikan benda-benda disekitarnya yang berinteraksi, dan kemudian dari peristiwa itu timbul konstruksi ide-ide yang mengantar pemahaman kita dan bermuara pada penemuan konsep, teori maupun fakta.

Dalam makna yang luas fisika diartikan sebagai sains atau ilmu tentang alam (natural science). Objek kajian ilmu fisika yaitu pada gejala alam yang tidak hidup atau materi dalam lingkup ruang dan waktu. Para Fisikawan telah mempelajari ilmu fisika yang dimulai dengan mengkaji perilaku dan sifat dasar materi dalam bidang yang sangat beragam, mulai dari tinjauan partikel secara submikroskopis yang membentuk segala materi (fisika partikel) hingga pada tinjauan perilaku materi alam semesta sebagai satu kesatuan kosmos.

Beberapa sifat yang dipelajari dalam fisika merupakan sifat yang dimiliki oleh semua sistem materi yang ada yang kemudian dipandang sebagai hukum fisika. Sebagai contoh, hukum kekekalan energi, hukum kekekalan massa dan hukum kekekalan momentum. Jadi, ilmu fisika sering dipandang sebagai ilmu paling mendasar bagi cabang ilmu alam lainnya seperti biologi, kimia, geologi, fisiologi, anatomi dan lain sebagainya yang juga mempelajari jenis sistem materi tertentu yang mematuhi hukum fisika. 
Tinjauan terhadap ilmu fisika secara lebih mendalam dari sisi historisnya tidak terlepas dari perkembangan ilmu fisika secara periodik, yakni mulai dari tinjauan fisika secara klasik hingga pada tinjauan secara modern, dimana pada setiap periode muncul ahli-ahli fisika dengan sudut pandangnya masing-masing yang mencoba mengungkap gejala alam yang didasari pada pemikiran yang realistis dan hasil eksperimen yang dilakukan. Perkembangan ilmu fisika juga ditentukan dari hasil eksperimen fisikawan terdahulu pada setiap masanya yang terus mengalami perkembangan hingga pada masa ini.

Dari teori-teori dan temuan para ahli untuk setiap masa menjadi dasar perkembangan ilmu fisika di masa-masa yang akan datang, sebagai contoh alasan runtuhnya fisika klasik karena ketidakmampuan fisika klasik menjelaskan fenomena-fenomena alam yang terjadi seperti tinjauan terhadap kecepatan elektron yang relatif tinggi menghampiri kecepatan cahaya. Alasan-alasan seperti ini akhirnya memicu munculnya teori-teori baru seperti radiasi benda hitam oleh Max planck, efek foto listrik dan teori relativitas oleh Albert Einstein yang mendasari timbulnya fisika modern sebagai solusi terhadap kelemahan yang dimiliki oleh fisika klasik.

Ilmu fisika harus terus mengalami perkembangan, hal ini menuntut ilmu fisika harus bersifat dinamis, tidak stagnan. Sebab ilmu fisika harus terus mengikuti perkembangan zaman, mengapa? Karena perkembangan pengetahuan dan teknologi yang semakin pesat merupakan berkat dari perkembangan ilmu fisika dan kolaborasinya dengan ilmu pengetahuan lainnya. Oleh karena itu, ilmu fisika harus terus mengalami perkembangan agar tetap eksis disetiap masa dan sesuai dengan realita kehidupan yang sesungguhnya.

Menyikapi perkembangan ilmu pengetahuan dan teknologi, sangatlah penting bagi kita untuk melakukan eksperimen yang bertujuan untuk membuktikan kebenaran suatu konsep, teori maupun temuan di dalam ilmu fisika yang telah dikemukakan oleh para ahli sebelumnya agar eksistensi ilmu pengetahuan disetiap masa tetap terlestarikan. Dalam penelitian ini penulis tertarik untuk meneliti besar nilai gravitasi bumi di kabupaten Sumba Barat Daya karena belum pernah dilakukan penelitian tentang hal ini. Oleh karena itu, pada penelitian ini peneliti ingin menghitung dan membuktikan besar nilai tetapan gravitasi bumi melalui suatu eksperimen sederhana dengan menggunakan alat peraga berupa bandul matematis di Kabupaten Sumba Barat Daya.

\section{Metode Penelitian}

Jenis penelitian yang di gunakan adalah penelitian eksperimen murni. Jumlah titik pengambilan sampel pada penelitian ini adalah sebanyak 11 titik yang tersebar di seluruh kecamatan yang berada di kabupaten Sumba Barat Daya. Berikut disajikan titik lokasi pengambilan data, seperti pada table berikut.

Tabel 1. Ketinggian Wilayah beberapa tempat di SBD

\begin{tabular}{|l|l|c|}
\hline No & \multicolumn{1}{|c|}{ Kecamatan } & $\begin{array}{c}\text { Tinggi Wilayah } \\
\text { (mdpl) }\end{array}$ \\
\hline 1. & Kodi Bangedo & $0-300$ \\
\hline 2. & Kodi Balaghar & $0-300$ \\
\hline 3. & Kodi & $0-300$ \\
\hline 4. & Kodi Utara & $0-300$ \\
\hline 5. & Wewewa Selatan & $300-500$ \\
\hline 6. & Wewewa Barat & $300-750$ \\
\hline 7. & Wewewa Timur & $300-850$ \\
\hline 8. & Wewewa Tengah & $300-850$ \\
\hline 9. & Wewewa Utara & $100-600$ \\
\hline 10. & Loura & $0-300$ \\
\hline 11. & Kota & $0-300$ \\
\hline
\end{tabular}

\section{Alat dan Bahan Pengambilan Data}

Alat dan bahan yang digunakan dalam pengambilan data pada penelitian ini adalah sebagai berikut.

Tabel 2. Alat dan Bahan

\begin{tabular}{|l|l|l|}
\hline \multicolumn{1}{|c|}{ Alat/bahan } & $\begin{array}{l}\text { Jumla } \\
\text { h }\end{array}$ & \multicolumn{1}{|c|}{ Fungsi } \\
\hline Statip & 1 set & $\begin{array}{l}\text { Tempat } \\
\text { menggantungkan } \\
\text { beban }\end{array}$ \\
\hline penjepit statip & 1 set & $\begin{array}{l}\text { Untuk menjepit } \\
\text { statip lainnya } \\
\text { pada statip utama }\end{array}$ \\
\hline Tali & 1 gulung & $\begin{array}{l}\text { Sebagai media } \\
\text { untuk } \\
\text { menggerakkan } \\
\text { beban sehingga } \\
\text { dapat berosilasi }\end{array}$ \\
\hline Beban 50 gram & 1 buah & $\begin{array}{l}\text { Objek yang akan } \\
\text { di amati geraknya }\end{array}$ \\
\hline Stopwatch & 1 buah & $\begin{array}{l}\text { Untuk mengukur } \\
\text { waktu osilasi } \\
\text { bandul }\end{array}$ \\
\hline
\end{tabular}




\begin{tabular}{|l|l|l|}
\hline Mistar 50 cm & 1 buah & $\begin{array}{l}\text { Untuk mengukur } \\
\text { panjang tali }\end{array}$ \\
\hline Busur derajat & 1 buah & $\begin{array}{l}\text { Untuk mengukur } \\
\text { besar sudut }\end{array}$ \\
\hline Alas statif & 2 buah & $\begin{array}{l}\text { Tempat } \\
\text { penyangga batang } \\
\text { statif }\end{array}$ \\
\hline Batang statif $50 \mathrm{~cm}$ & 1 buah & $\begin{array}{l}\text { Tempat } \\
\text { menggantungkan } \\
\text { beban }\end{array}$ \\
\hline Batang statif $20 \mathrm{~cm}$ & 2 buah & $\begin{array}{l}\text { Penghubung } \\
\text { antara kedua alas } \\
\text { statif }\end{array}$ \\
\hline
\end{tabular}

\section{Langkah Pengambilan Data}

Susunan alat peraga bandul sederhana terdiri atas beban bermassa $m$ dan tali yang panjangnya L (tali dianggap tak bermassa). Ada dua cara yang digunakan peneliti dalam mengumpulkan data yakni: Pengambilan data dilakukan saat beban berosilasi. Langkahlangkah pengambilan data yaitu:

1. Mempersiapkan alat dan bahan yang akan digunakan dalam percobaan

2. Mengikat beban dengan tali benang kemudian benang dipotong sesuai dengan panjang yang dibutuhkan

3. Mengukur sudut simpangan antara tali dan statip. Pada penelitian ini sudut yang digunakan adalah $15^{\circ}$.

4. Melepaskan beban untuk berayun. Pada saat yaang bersamaan ketika kita melepaskan beban kita juga menekan stop watch untuk mengukur waktu ayunan bandul. Pengukuran waktu ayunan bandul disesuaikan dengan jumlah ayunan bandul yang dibutuhkan $(\mathrm{n}=$ 10 kali). Pemilihan jumlah ayunan bandul sebanyak sepuluh kali di maksudkan agar data yang diperoleh dari hasil analisis lebih akurat.

5. Mencatat waktu yang ditunjukan oleh stopwatch ketika bandul sudah berosilasi sesuai dengan jumlah ayunan yang di perlukan.

6. Mengulangi langkah 2 dengan variasi panjang tali yang berbeda, kemudian dilanjutkan dengan langkah 3, 4 dan 5.

Data-data hasil eksperimen berupa

pengukuran panjang tali dan waktu yang dibutuhkan benda saat berosilasi dianalis dengan menggunakan metode "least square".

\section{Hasil dan Pembahasan}

Pengumpulan data dilakukan secara langsung oleh peneliti dengan menggunakan alat berupa bandul. Langkah-langkah yang di tempuh sesuai dengan prosedur penelitian. Analisis data menggunakan Microsoft excel dimana nilai $X$ merupakan variasi panjang tali dan Y merupakan rata-rata kuadrat periode osilasi bandul. Berikut adalah grafik hasil tabulasi data dengan menggunakan excel untuk tiap titik sampel.
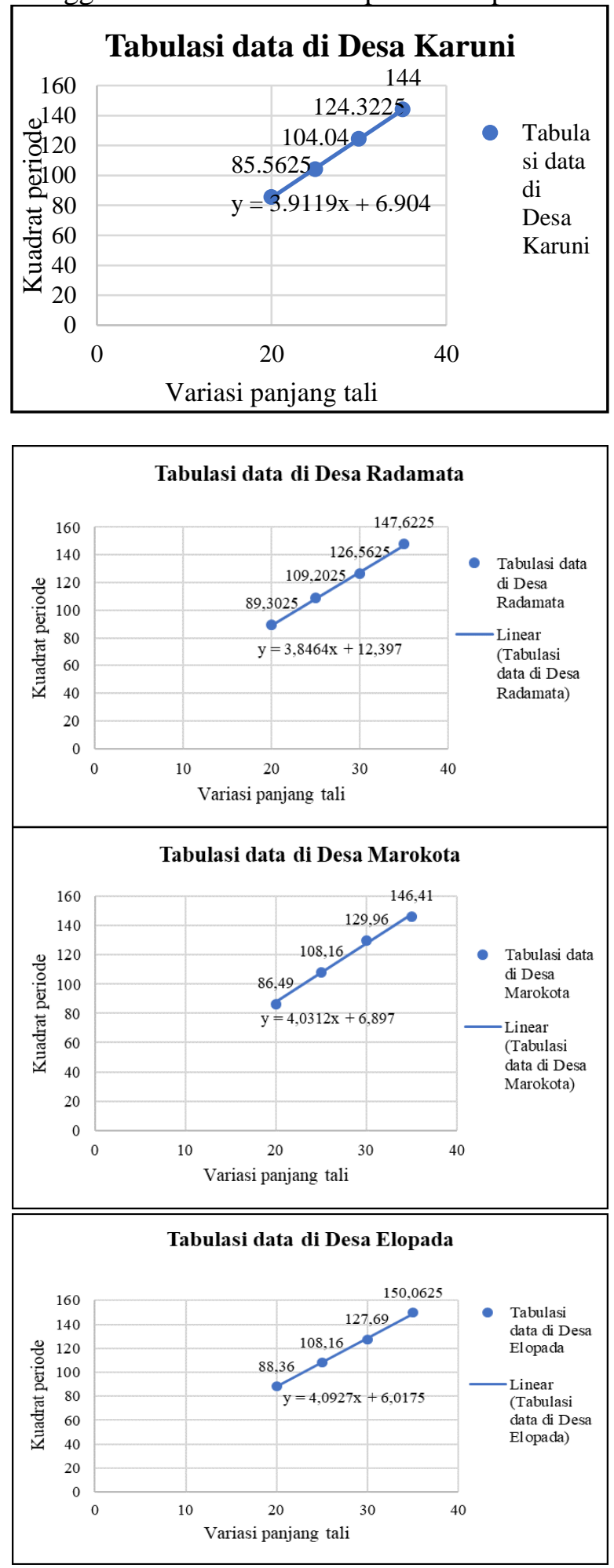

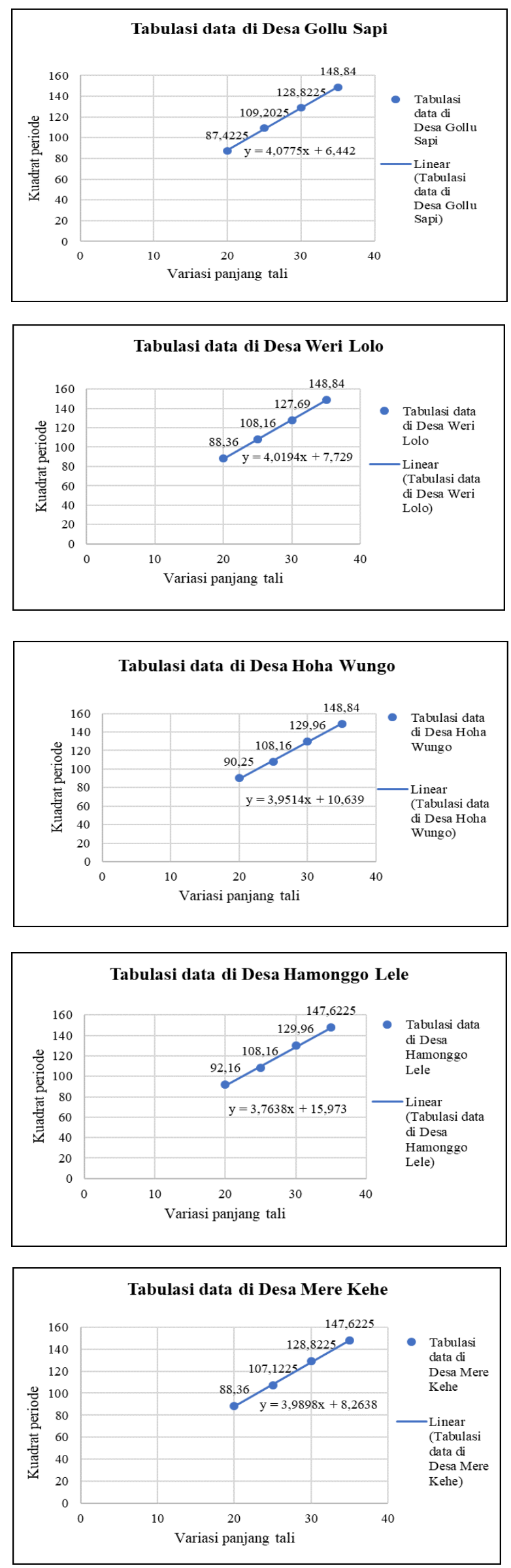

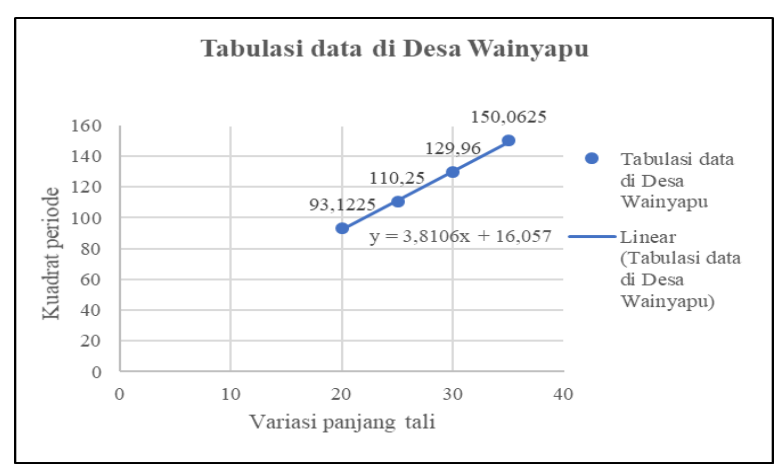

\section{Pembahasan}

Berdasarkan data yang diperoleh saat pengambilan sampel di setiap titik kecamatan yang telah ditentukan dan dari hasil analisis grafik exel yang telah memberikan nilai fitting grafik untuk setiap titik pengambilan sampel, maka ratarata nilai gravitasi bumi Kabupaten Sumba Barat Daya dapat di hitung dengan persamaan:

$$
\begin{gathered}
\sum_{n=1}^{10} g_{n}=\frac{g_{1}+g_{2}+g_{3}+g_{4}+\cdots+g_{n}}{n} \\
g_{i}=\frac{10,07+10,23+9,77+9,63+9,65+9,8+9,97+10,47+9,87+10,34}{10} \\
g_{i}=\frac{99,8}{10}=9,98 \mathrm{~m} / \mathrm{s}^{2}
\end{gathered}
$$

Berdasarkan hasil yang diperoleh dari perhitungan tersebut di ketahui bahwa rata-rata besar gravitasi bumi di Kabupaten Sumba Barat Daya adalah $9,98 \mathrm{~m} / \mathrm{s}^{2}$. Nilai tersebut sangat sesuai dengan konstanta umum gravitasi bumi.

Hubungan Ketinggian dan nilai Percepatan gravitasi bumi

Tabel 3. MDPL dan nilai $g$

\begin{tabular}{|l|c|c|}
\hline \multicolumn{1}{|c|}{ Desa } & MDPL (m) & $\begin{array}{c}\text { Gravitasi } \\
\left(\mathbf{m} / \mathbf{s}^{2}\right)\end{array}$ \\
\hline Karuni & 68 & 10,07 \\
\hline Radamata & 56 & 10,23 \\
\hline Elopada & 486 & 9,63 \\
\hline Marokota & 444 & 9,77 \\
\hline Gollu Sapi & 486 & 9,65 \\
\hline Weri Lolo & 382 & 9,8 \\
\hline Hoha Wungo & 88 & 9,97 \\
\hline Mere Kehe & 137 & 9,87 \\
\hline Hamonggo Lele & 47 & 10,47 \\
\hline Wainyapu & 49 & 10,34 \\
\hline
\end{tabular}

Dari table tersebut di atas diperlihatkan bahwa terdapat hubungan berbanding terbalik atau tak senilai antara ketinggian wilayah dengan 
nilai percepatan gravitasi yang diperoleh. Dari 11 titik lokasi pengambilan data, daerah yang memiliki ketinggian yang lebih rendah dari titik yang lain adalah desa Hamonggo Lele yaitu 47 MDPL dengan nilai $g$ yang diperoleh adalah 10,47 $\mathrm{m} / \mathrm{s}^{2}$. Daerah tertinggi yang memiliki nilai ketinggian yang sama adalah desa Elopada dan desa Weri Lolo dengan nilai g secara berturutturut adalah $9,63 \mathrm{~m} / \mathrm{s}^{2}$ dan $9,65 \mathrm{~m} / \mathrm{s}^{2}$. Dari hasil ini menunjukan bahwa semakin tinggi nilai MDPL maka nilai percepatan gravitasi bumi akan semakin kecil dan juga sebaliknya semakin rendah nilai MDPL maka percepatan gravitasi bumi akan semakin besar.

Hal ini sangat sesuai dengan teori gravitasi bumi yang telah berkembang dan kesimpulan yang di kemukakan oleh Newton bahwa gaya gravitasi yang diberikan oleh Bumi pada setiap benda akan berkurang menurut nilai kuadrat dari jarak $r$ benda itu ke pusat Bumi yang secara matematis di nyatakan dalam persamaan:

$$
F_{G} \propto \frac{1}{r^{2}} \ldots \ldots \ldots \ldots . . .(\text { Giancoli, 2014). }
$$

\section{Kesimpulan}

Berdasarkan uraian hasil penelitian dan pembahasan dapat ditarik kesimpulan bahwa terdapat perbedaan nilai gravitasi bumi pada beberapa tempat di Kabupaten Sumba Barat Daya. Untuk daerah dengan ketinggian di bawah 100 meter dari permukaan laut memiliki rata-rata gravitasi bumi sebesar $10,2 \mathrm{~m} / \mathrm{s}^{2}$ dan daerah dengan ketinggian di atas 100 meter memiliki rata-rata nilai gravitasi bumi sebesar $9,7 \mathrm{~m} / \mathrm{s}^{2}$. Dari hasil analisis grafik nilai gravitasi bumi untuk setiap titik di ketahui bahwa rata-rata gravitasi bumi di Kabupaten Sumba Barat Daya adalah $9,98 \mathrm{~m} / \mathrm{s} 2$. Nilai gravitasi bumi di setiap titik pengambilan sampel berbeda-beda karena dipengaruhi oleh perbedaan ketinggian, dapat juga diketahui bahwa nilai percepatan gravitasi terkecil adalah pada desa elopada sebesar 9,63 $\mathrm{m} / \mathrm{s}^{2}$ dan nilai percepatan gravitasi bumi terbesar adalah pada desa Hamonggo Lele dengan nilai $10,47 \mathrm{~m} / \mathrm{s}^{2}$.

\section{Saran}

Saran dalam penelitian ini adalah agar penelitian selanjutnya dapat mengambil sampel di setiap titik berdasarkan peta kontur yang dioleh menggunakan software ARCGIS agar ketinggi wilayah dapat di kabupaten Sumba Barat Daya dapat diketahui secara keseluruhan.

\section{Daftar Pustaka}

Afifah Nur Disah, dkk. (2015). Metode sederhana menentukan percepatan gravitasi bumi menggunakan aplikasi tracker pada gerak parabola sebagai media dalam pembelajaran fisika SMA. Prosiding symposium nasional inovasi dan pembelajaran sains 2015.

Chusni, Minan, Muhammad. (2017). Penentuan besar percepatan gravitasi bumi menggunakan ayunan matematis dengan berbagai metode pengukuran. Jurnal Pendidikan sains, vol. 6 (1): 47 -53.

Chusni, M. M. (2017). Penentuan Besar Percepatan Gravitasi Bumi Menggunakan Ayunan Matematis dengan berbagai metode pengukuran. Scientiae Educatia:Jurnl Pendidikan Sains , 6, 47-53

Daya, B. P. (2020). Kabupaten Sumba Barat Daya dalam angka 2020. Sumba Barat Daya: Badan Pusat Statistik Kabupaten Sumba Barat Daya.

Faryanto, Suritno. (2016). Penentuan percepatan gravitasi bumi dengan metode bandul sederhana. Jurnal praktikum mekanika analitik.

Giancoli, C.Douglas. 2014. Fisika Prinsip dan Aplikasi (Edisi ketujuh jilid 1). Jakarta: Erlangga.

Giancoli, Douglas C. 2007. Fisika Dasar Jilid Satu Edisi Kelima. Jakarta: Erlangga.

Halliday. 2005. Fisika Dasar. Jakarta: Erlangga.

Jusmi, F. (2011). Studi tentang unit eksperimen momen inersia pada bidang miring dan unit eksperimen ayunan bandul dalam menentukan percepatan gravitasi bumi. jurnal dinamika , 02, 42-50.

Kartika Widyaningrum, t. p. (2015). Penentuan percepatan gravitasi bumi lokal dengan bantuan sistem pegasmassa dan sensor ultrasonik. inovasi fisika indonesia , 04, 55-60.

Radianto, Haris. (2017). Penentuan percepatan gravitasi pada percobaan gerak jatuh bebas dengan memanfaatkan rangkaian relai. Jurnal Fisika dan aplikasinya.

Suritno Fayanto, Y. S. (2016). Penentuan Percepatan Gravitasi Bumi dengan metode Bandul Sederhana. Praktikum Mekanika Analitik Laboratorium Jurusan Pendidikan Fisika Universitas Halu Uleo, 1-19.

Sugiyono. (2014). Metode Penelitian 
Pendidikan Pendekatan Kuantitatif, Kualitatif, dan $R \& D$. Bandung: Alfabeta.

Tripler, P.A.,(1998). Fisika: untuk sains dan teknik. Jakarta: Erlangga

Untari, D. T. (2018). Buku Ajar Metodologi Penelitian (penelitian kontemporer bidang ekonomi dan bisnis). Jawa Tengah: CV. Pena Persada.

Widyaningrum, Kartika, dkk. (2015). Penentuan percepatan gravitasi bumi local dengan bantuan system pegas - massa dan sensor ultrasonic. Jurnal inovasi fisika Indonesia, vol.04, no. 03, 2015. p.55-60. 